\title{
Histopathological spectrum of cervical biopsies - a 5 year retrospective study
}

\author{
Kumari K ${ }^{1}$, Umarani M.K ${ }^{2}$, Bharathi $\mathbf{M}^{3}$ \\ ${ }^{1}$ Dr Kanya Kumari, Postgraduate, ${ }^{2}$ Dr Umarani M.K, Associate Professor, ${ }^{3}$ Dr Bharathi M, Professor and HOD, Mysore \\ Medical College and Research Institute, Mysuru, Karnataka 570001, India.
}

Address for Correspondence: Dr Kanya Kumari, E- mail id: drkanyakumari1 @ gmail.com.

\begin{abstract}
Introduction: cervix is a gateway to numerous non neoplastic and neoplastic gynecological lesions. Cervical cancer is the leading cancer in Indian women and second most common cancer in women worldwide next to breast cancer. Objectives: 1) To study the histopathological features of cervical lesions. 2) To study the age distribution and relative frequency of various cervical lesions. Materials and Methods: This is 5 years retrospective study of all cervical biopsies received from 2011-2015 in the department of pathology. Result: In a total of 739 cases studied 365(49.39\%) cases were non neoplastic, 113(15.29\%) were pre invasive and 261(35.31\%) cases were malignant. Cervicitis was the most common non neoplastic lesion and squamous cell carcinoma was the most common cancer. Conclusion: Adequate cervical screening procedure with follow up cervical biopsies helps in early diagnosis and management of premalignant and malignant lesions.
\end{abstract}

Key words: Cervical cancer, Cervicitis, Neoplastic, Non- neoplastic

\section{Introduction}

Cervix is the elongated fibromuscular portion of uterus measuring $2.5-3 \mathrm{~cm}$, divided into ecto-cervix and endocervix which is lined by squamous epithelium and mucin secreting columnar epithelium respectively with a characteristic transformation zone in between [1].

Cervix is vulnerable to many pathological changes ranging from inflammation to malignancy. Uterine cervix is gateway to several non-neoplastic and neoplastic gynecological lesions [2].

Non neoplastic cervical lesions occur at all age groups amongst women but are more common in reproductive and sexually active women. Non neoplastic cervical lesions include inflammatory lesions and nonneoplastic tumor like lesions. Majority of these inflammatory lesions are acute cervicitis, chronic cervicitis caused by various bacteria, viruses and fungi [3]. Cervicitis caused by Human papilloma virus carries high risk for Condyloma acuminata, Crevical intraepithelial neoplasia (CIN) and carcinoma [4].

Manuscript received: $22^{\text {nd }}$ February 2017

Reviewed: $2^{\text {nd }}$ March 2017

Author Corrected: $9^{\text {th }}$ March 2017

Accepted for Publication: $15^{\text {th }}$ March 2017
Among non- neoplastic tumor like conditions are endocervical hyperplasia, endometriosis, polyps and Nabothian cysts [5].

Carcinomas of the female genital tract, particularly cervical carcinoma accounts for almost $12 \%$ of all cancers in women, and so represents the second most frequent malignancy in the world after carcinoma of breast [6]. Histopathological studies of cervix along with clinical correlation helps in early diagnosis of lesions as they have advantages of being relatively cheap and technically easy.

\section{Objectives}

1. To study the histopathological features of cervical lesions.

2. To study the age distribution and relative frequency of various cervical lesions.

\section{Materials and Methods}

All the uterine cervical biopsies received at the department of pathology of Mysore Medical College and Research Institute, Mysuru over a period of 5 years 
Research Article

included in the study. Information regarding each patient was obtained from patient's file or requisition forms.

Inclusion criteria: All cervical biopsies sent to the department of pathology from Jan 2011-Dec 2015.

Exclusion criteria: Cervical biopsies found to be unsatisfactory for evaluation on microscopic examination.

Total of 750 cases were received in 5 year time period. Out of which 11 cases were excluded based on above mentioned criteria. So a total of 739 cases were reviewed in this study

Methods: Slides were retrieved from the archives of the department of pathology. Wherever necessary new sections were made from formalin fixed paraffin embedded blocks and stained with Haematoxylin and Eosin.

All specimens were formalin-fixed and paraffin wax processed tissues. The specimens were fixed in $10 \%$ formalin and then processed. Tissue sections of 5micron thickness were obtained and stained with Hematoxyline and eosin and special stains wherever necessary.

Study method: Retrospective study.

Statistical methods: Data was entered in Excel sheet and values were obtained by frequency, proportion and chi-square test.

Ethical consent: The study was approved by the institutional ethical committee and research cell.

\section{Results}

In this 5 years of retrospective study total of 739 cases were studied from 2011 to 2015 . Out of these 365(49.39\%) cases were non neoplastic, 113(15.29\%) were pre invasive and 261(35.31\%) cases were malignant (Table no 1).

Malignant cases (Table no 4) constituted to $35.31 \%$ of cases. Most common type of carcinoma was squamous cell carcinoma noted in 246 cases and 8 cases of adenocarcinoma were noted. Neoplastic cases were more in $6^{\text {th }}$ decade. Other malignant cases noted were 2 cases of adenosquamous cell carcinoma and one each case of neuroendocrine carcinoma, embryonal rhabdomyosarcoma, adenoid basal cell carcinoma, malignant melanoma and undifferentiated carcinoma were noted.

Table No.-1: Distribution of lesions.

\begin{tabular}{|c|c|c|}
\hline Cervical lesions & Total & Percentage \\
\hline Non neoplastic (inflammatory and tumor like lesions) & 365 & $49.39 \%$ \\
\hline Pre-invasive cervical intraepithelial lesions & 113 & $15.29 \%$ \\
\hline Malignant lesions & 261 & $35.31 \%$ \\
\hline
\end{tabular}

Non neoplastic lesions were higher than neoplastic lesions. Non neoplastic lesions (Table no 2) included both inflammatory lesions and tumor like lesions. Inflammatory lesions (cervicitis) were seen in 316 cases and maximum number of cases seen in $4^{\text {th }}$ decade of life. Non neoplastic tumors like lesion such as polyps were seen in 49 cases.

Table-2: Distribution of non neoplastic lesion.

\begin{tabular}{|c|c|c|c|}
\hline Age & Cervicitis & Endocervical polyp & Leomyomatous polyp \\
\hline$<20$ & 1 & 0 & 0 \\
\hline $21-30$ & 76 & 2 & 3 \\
\hline $31-40$ & 111 & 14 & 4 \\
\hline $41-50$ & 75 & 7 & 0 \\
\hline $51-60$ & 31 & 0 & 0 \\
\hline $61-70$ & 14 & 0 & 0 \\
\hline $71-80$ & 6 & 0 & 14 \\
\hline$>80$ & 2 & 35 & 0 \\
\hline Total & 316 & 12 & 0 \\
\hline
\end{tabular}


A total of 113(15.29\%) Pre invasive cervical intraepithelial lesions (Table no 3) were seen and majorities were high grade squamous intraepithelial lesions, seen in $4^{\text {th }}$ decade. Cases of low grade squamous intraepithelial lesions were also higher in $4^{\text {th }}$ decade of life.

Table-3: Distribution of preinvasive cervical lesion Table no 4: Distribution of malignant case.

\begin{tabular}{|c|c|c|}
\hline Age & LSIL & HSIL \\
\hline$<20$ & 0 & 1 \\
\hline $21-30$ & 2 & 10 \\
\hline $31-40$ & 20 & 20 \\
\hline $41-50$ & 10 & 12 \\
\hline $51-60$ & 7 & 11 \\
\hline $61-70$ & 6 & 8 \\
\hline $71-80$ & 2 & 4 \\
\hline$>80$ & 0 & 0 \\
\hline TOTAL & 47 & 66 \\
\hline
\end{tabular}

\begin{tabular}{|c|c|c|}
\hline Age & SCC & Adenocarcinoma \\
\hline$<20$ & 0 & 0 \\
\hline $21-30$ & 8 & 1 \\
\hline $31-40$ & 56 & 2 \\
\hline $41-50$ & 55 & 3 \\
\hline $51-60$ & 67 & 2 \\
\hline $61-70$ & 52 & 0 \\
\hline $71-80$ & 11 & 0 \\
\hline$>80$ & 3 & $\mathbf{8}$ \\
\hline
\end{tabular}

\section{Discussion}

Cervical biopsies constitute the major bulk of specimens received in the department of pathology.

Chronic non- specific cervicitis was the most common non neoplastic lesion seen in 316 cases $(86.57 \%)$, comparable to the study done by Badge et al [7]. Maximum cases were seen in age group of 31-40 yrs. Diagnosis of chronic cervicitis was made on the presence of lymphoplasmacytic infiltrate, some cases also showed areas of squamous metaplasia.

Infective causes of cervicitis includes wide spectrum of organisms ranging from bacterial, viral, protozoan and fungi, microorganisms commonly encountered in sexually transmitted infections (STIs) and urinary tract infections (UTIs). Studies have shown that chronic granulomatous cervicitis is mostly caused by tuberculosis [2]. Paavonen J et al [8] has stated that the etiology of chronic non- specific cervicitis is variable and it is of importance because it may lead to endometritis, salphingitis and "pelvic inflammatory disease" through ascending intraluminal spread, chorioamnionitis and it may also play a role, in the initiation or promotion of cervical neoplasia.

Non-neoplastic tumors like lesions such as polyps (endocervical/ leiomyomatous) were rare entity seen in 49(13.42\%) cases. A study done in tertiary care hospital by Saravana et al [3] also found polyps in only $6.5 \%$ of cases. Histopathological diagnosis of endocervical polyps were made based on the presence of dilated endocervical glands and blood vessels in the stroma in section studied. Polyps which showed subepithelial smooth muscle arranged in interlacing fascicles were diagnosed as leimyomatous polyp.

Squamous intraepithelial lesions are the clinical and morphological manifestation of a productive Human Papilloma Virus (HPV) infection. 
Research Article

In our study15.29\% of the cases showed cervical squamous intraepithelial lesions of which majority of cases were high grade lesions seen in $4^{\text {th }}$ decade. Sections of cervical biopsies displaying cytological abnormality in lower $1 / 3^{\text {rd }}$ of the epithelium were diagnosed as low grade squamous intraepithelial lesion and dysplasia in lower $2 / 3^{\text {rd }}$ or full thickness of the cervical epithelium were diagnosed as high grade squamous intraepithelial lesion (HSIL) (Figure 1).

Study done by Singh et al [9] found 20\% prevelance of squamous intraepithelial lesion comparable to the present study. A more aggressive approach in the management of these lesions is warranted, because progression to invasive carcinoma is higher in these lesions.

The outcome for patients with LSIL is excellent as regression is expected on average within approximately one year. Infection with HPV16 is associated with high risk of progression of LSIL to HSIL or worse and positive p16 immunochemistry is suggestive of increased risk of progression [10]. But no single or combination markers have been found to predict definitely whether a given lesion will progress, persists or regress.

Most of the Patients with HSIL are cured by Loop electrosurgical Excision Procedure (LEEP) and surgical conization procedure but size of the lesion, completeness of excision predicts recurrence. HPV DNA at 12 months post therapy is the best predictor of recurrence or relapse of residual disease [10].

Out of the different histopathological types of cervical cancer, squamous cell carcinomas account for $75-80 \%$ of cervical cancers, adenocarcinoma $15-25 \%$, and adenosquamous carcinomas 3-5\% [11].

Adenocarcinomas have been rising in incidence since the 1970s; especially in women younger than 35 years of age. Part of the increase may be attributable to an increasing prevalence of human papilloma virus (HPV) infection [12].

Amongst the neoplastic lesions squamous cell carcinoma (SCC) was the commonest (94.25\%) lesion, comparable to study done by Gupta et al [13] (94.26\%). SCC was seen predominantly seen in age group of 50-60 years. Diagnosis of SCC was made based on the presence of invasive nests of dysplastic squamoid cells infiltrating the basement membrane and invading the stroma. Also seen were keratin pearl formation in numerous cases and some of the cases showed moderately differentiated squamous cell carcinoma.

In the present study only $8(3.06 \%$ ) cases of adenocarcinoma (Figure no 2 ) were noted and one case each of malignant melanoma, rhabdomyosarcoma, neuroendocrine carcinoma, adenosquamous carcinoma, undifferentiated carcinoma and a case of adenoid basal cell carcinoma was reported.

Case of embryonal rhabdomyosarcoma (RMS) was noted in female aged 30 years. Rhabdomyosarcoma is a malignant neoplasm arising from skeletal muscle progenitors. Embryonal rhabdomyosarcoma of the uterine cervix are rare tumors.almost $70 \%$ of all RMS are diagnosed before 20 years of age. However they do typically occur in adult patients [14]. The diagnosis of RMS was made in 30 year female based on the presence of round to spindle cells with delicate tail of eosinophilic cytoplasm, seen beneath the epithelium of cervix. One case of neuroendocrine carcinoma (Figure no 3) was seen female aged 38 years. Histopathology showed cells arranged in trabecule, nested and organoid pattern with salt and pepper chromatin, diagnosis was confirmed in higher center after performing Immunohistochemical studies.

Primary malignant melanoma of uterine cervix is rare neoplasm of female genital tract, less than 50 cases reported in literature [15]. Most of the patients present in later stage and respond poorely to treatment [16]. Melanoma in uterine cervix may be melanotic or amelanotic composed of cells with variable degree of plomorphism and eosinophilic nucleoli.

About half of all mucosal melanoma are amelanotic and in these cases poorely differentiated scc, adenocarcinoma and rhabdomyosarcoma and stromal sarcoma must be ruled out [15] In present study also, we noted a single case in a 60 year female who presented with blackish mass per vagina since 4 months. Histopathological examination of tissue showed sheets of pleomorphic tumor cells with hyperchromatic nucleus and prominent eosinophilic nuceoli . The interstitium and cytoplasm of cells showed a dense pigmentation suggestive of malignanat melanoma, and was confirmed by Masson 
Fontana staining. Even after thorough clinical investigations there was no evidence of primary lesion elsewhere in the body so it was reported as primary malignant melanoma of cervix (Figure no 4).

Incidence of malignancy was much higher(35.31\%) in our study compared to other studies may be due to Women failed to be screened and were unable to access health care delivery system, due to insufficient resources, lack of knowledge, and poor socioeconomic status.

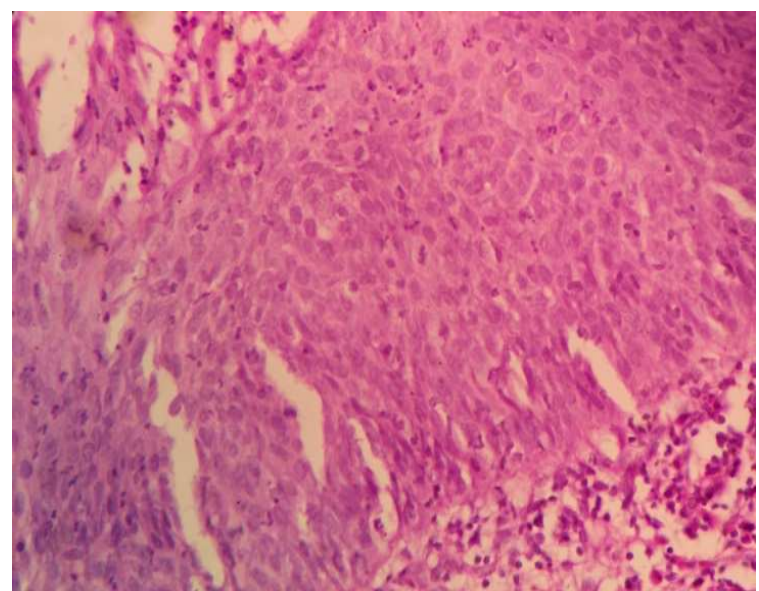

Figure No-1: HSIL

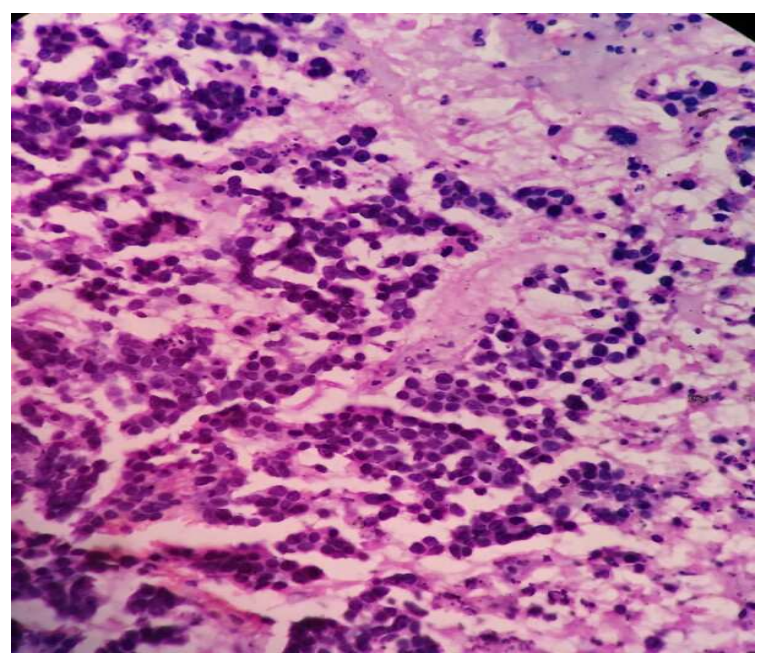

Figure No-3: Neuroendocrine carcinoma

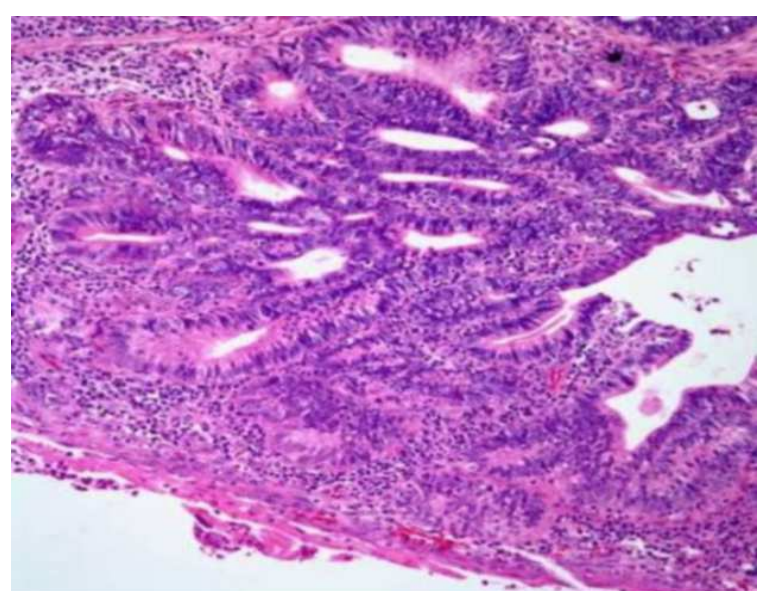

Figure No-2: Adenocarcinoma of cervix

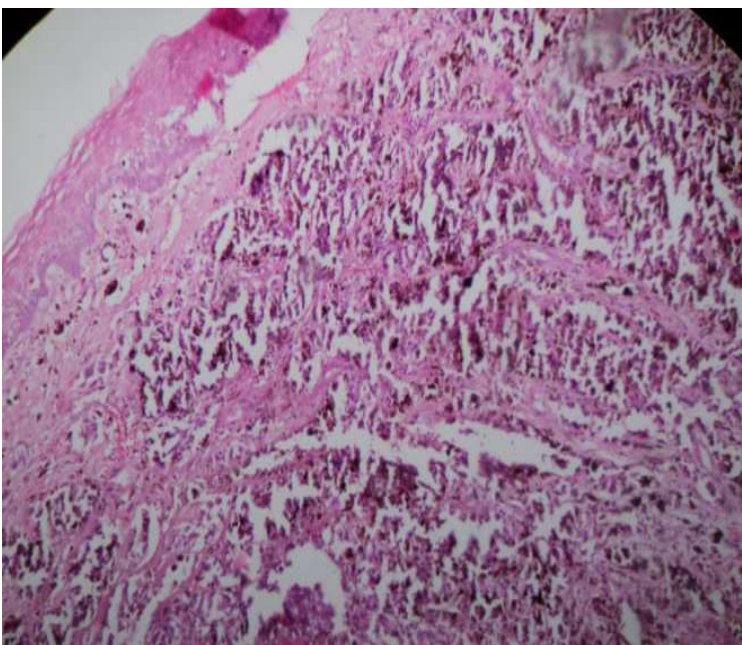

Figure No-4: Malignant melanoma

\section{Conclusion}

- In our study non neoplastic lesions were more common than neoplastic lesions. Chronic cervicitis was the most common lesion followed by malignancy and squamous intraepithelial lesion.

- Cervical lesions constitute the major source of mortality and morbidity if they are not detected and treated early.

- Cervical biopsy helps in definitive diagnosis of lesions.

- Cases of cervicitis should be treated promptly to prevent further complications.

- Low grade Squamous intraepithelial lesions should be followed up with HPV DNA testing and p16 immunohistochemistry and observation and HSIL with LEEP, conization and HPV DNA testing.

- Adequate screening procedure with follow up cervical biopsies helps in early diagnosis and management of premalignant and malignant lesions.

Funding: Nil, Conflict of interest: None initiated,

Permission from IRB: Yes 


\section{References}

1. Mahgoub et al.Histopathological pattern of cervical lesions at Omdurman Military hospital,Sudan.Sch. J. App. Med. Sci.2015 Nov; 3(8C):2903-2907.

2. Nwachokor FN, Forae GC. Morphological spectrum of non-neoplastic lesions of the uterine cervix in Warri, South-South, Nigeria. Niger J Clin Pract. 2013 OctDec; 16(4):429-32. doi: 10.4103/1119-3077.116883.

3. Srivani Saravanan, Jonathan Arnold, Arul P. "Histomorphological Spectrum of Lesions of the Cervix, A Retrospective Study in a Tertiary Care Hospital". Journal of Evolution of Medical and Dental Sciences 2015; July 4(59) : 10326-10329.

4. Bosch FX, Lorincz A, Muñoz N, Meijer CJ, Shah $\mathrm{KV}$. The causal relation between human papillomavirus and cervical cancer. J Clin Pathol. 2002 Apr;55(4): 244-65.

5. Simionescu C, Mărgăritescu C, Georgescu CV, Mogoantă L, Marinescu AM. Pseudo-tumoral lesions of the cervix. Rom J Morphol Embryol. 2005; 46(3): 239-47.

6. Jain A, Jain R, Iqbal, G Kotteswaran, S Dhananjay, Kamble T .Histopathological study of tumors of cervix. Advances in cancer research and therapy 2014.;1(2) : $1-8$.

7. Bagde S, Gupta R, Ganguly S, Bhardwaj A, Jogi S. "Spectrum of Cervical Lesions in CIMS, Bilaspur: A 5 Year Retrospective Study of 215 Cases in a Tertiary Hospital of Central India". Journal of Evidence based Medicine and Healthcare.2015 Oct19; 2(42):7505-7510

8. Paavonen J, Critchlow CW, DeRouen T, Stevens CE, Kiviat N, Brunham RC, Stamm WE, Kuo CC, Hyde KE, Corey L, et al. Etiology of cervical inflammation. Am J Obstet Gynecol. 1986 Mar;154(3):556-64.
9. Singh VK, Das R. Cervical neopiasms diagnosed by toludine blue, Exfoliative cytology and• Histology. J Obstel Gynecol Ind. 1983; 33: 116.

10. Robert J. Kurman, Maria Luisa Carcangiu, C Simon Herrington, Robert H. Young,(Eds): WHO Classification of tumors of female Reproductive Organs. IARC: Lyon 2014 NEW

11. Berrington D, Gonzalez A, Green J, Comparison of risk factors for invasive squamous cell carcinoma and adenocarcinoma of the cervix collaborative reanalysis of individual data on 8,097 women with squamous cell carcinoma and 1,374 women with adenocarcinoma from 12 epidemiological studies, Int J. Cancer, 2007; 120 (4): 885-891.

12. Grisaru D, Covens A, Chapman B, Shaw P, Colgan $\mathrm{T}$, Murphy J, et al., Does histology influence prognosis in patients with early-stage cervical carcinoma?, Cancer, 2001; 92(12): 29993004.

13. Gupta S, Rao MC, Gupta IM, Gupta YN, Khanna S, Sanyal SK, Prakash A. Cervix correlated cytohistological study. Indian J Pathol Microbiol. 1979 Apr; 22 (2):93-6.

14. Dehner L P, Jarzembowski J A, Hill D A. Embryonal rhabdomyosarcoma of the uterine cervix;a report of 14 cases and discussion of its unusual clinicopathological association.Modern pathology. 2012 25,602-614.

15. Gupta R, Singh S, Mandal AK. Primary malignant melanoma of cervix - a case report. Indian J Cancer. 2005 Oct-Dec; 42(4):201-4.

16. Dematos P, Tayler D, Seigler H F.Mucosal melanoma of female genitelia:a clinicopathological study of forty nine cases at Duke University Medical Center. Surgery 1998;124:38-48.

\section{How to cite this article?}

Kumari K, Umarani M.K, Bharathi M. Histopathological spectrum of cervical biopsies - a 5 year retrospective study. Trop J Path Micro 2017;3(1):46-51.doi: 10.17511/jopm.2017.i1.08. 